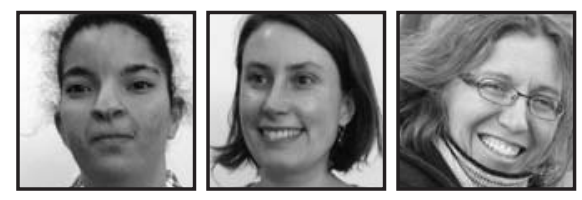

\title{
Project Capabilities and Adults With Intellectual Disabilities: Towards Effective Interviewing for a Better Social Participation
}

\author{
Stefanie Corona, Christina Hannum, and Ann-Louise Davidson, \\ Concordia University
}

\section{ABSTRACT}

This practice-based paper presents a series of tips and techniques for interviewing for a better social participation. While we worked on Project Capabilities, we learned valuable lessons we wished to share with practitioners and researchers who work within an inclusive perspective. We argue that qualitative interviewing requires skillful means that are not always an integral part of research preparation, and we share tips and techniques that we developed throughout the process. As we collected the qualitative data through one-on-one interviews, and taught participants to selffilm using iPads, we found that traditional interviewing techniques were too rigid to engage with people living with an intellectual disability. Instead, we used a blend of motivational interviewing and collaborative inquiry techniques, and built rapport with the participants through online social networking. Mobile technologies were also used to build rapport, empowering participants and allowing non-intrusive filming of interviews.

\section{Introduction}

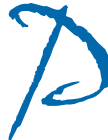

roject Capabilities is a collaborative action research which relies on Sen's (1992) and Nussbaum's (2000) capabilities approach to help adults living with an intellectual disability (ID) become better self-advocates and serve as role models to other adults living with an ID. The capabilities approach (Nussbaum, 2000; 
Sen, 1992) focuses on what individuals are able to do, as opposed to what they are not able to do. Using the capabilities approach shifts the dialogue around adults living with an ID from one of deficiency and dependency to one of empowerment, enabling them to make their own life choices and decisions by helping them to access the tools they need to reach their goals. Project Capabilities builds on 10 years of research with people with intellectual disabilities, which has relied on collaborative action research to help this population become better integrated into their communities (Davidson, 2009a, 2009b, 2009c; Davidson, 2012; Davidson, Leblanc, Leno, Clément, Godbout, et al., 2004; Leblanc, Paruthi, Davidson, Clément, Godbout, et al., 2008).

In this particular study, our research team collaborated with eight adults with light to moderate intellectual disabilities to co-create self-advocacy videos. These individuals wanted to become better self-advocates with the ultimate goal of empowering themselves and others, and breaking down the stigma against adults with intellectual disabilities within the broader community. The researchers collected qualitative data through a series of one-on-one interviews with each participant. Interviews were used to help set goals for the participants' self-advocacy work, and to enable them to identify elements of their own lives they were proud of that could serve as an inspiration to others. Mobile technologies (i.e., iPads and iPhones) were used to facilitate communication between the researchers and participants, and as tools to co-create self-advocacy videos that could be shared with the broader community via mobile technologies and social media platforms.

The research team read about interviewing techniques in several well-known research textbooks, including Qualitative Interviewing: The Art of Hearing Data by Herbert J. Rubin and Irene S. Rubin (2012), and Educational Research: Planning, Conducting, and Evaluating Quantitative and Qualitative Research by John W. Creswell (2008). While these works provide good structured procedures for collecting qualitative data, their approaches tend to be very rigid. Creswell (2008), for example, suggests that the researcher should prepare a list of specific interview questions before an interview, and that each participant should answer all questions. He further suggests that interviews should be directed from the interviewer to interviewee, and advises the interviewer to "keep your opinions to yourself" (p. 238). In contrast, we found that motivational interviewing techniques proved to be more effective for interviewing adults with intellectual disabilities. Motivational interviewing relies on skills such as knowing how to ask open-ended questions, affirming, and reflective listening (Miller \& Rollnick, 2013). We found these techniques to be invaluable as we prepared to conduct the interviews. 
The reader should be reminded that this article focuses on our approach to interviewing people with intellectual disabilities rather than on the data we collected. In the next section, we describe the process we used to interview the participants, and some of the lessons we learned from the experience that can serve as helpful tips for interviewing fragile populations efficiently. We start by describing our recruitment approach, which was instrumental to the success of this study, and the blend of interviewing techniques we used during each phase of data collection.

\section{Recruiting Participants}

We recruited a total of eight adults (two females and six males) who take part in organizations that work with adults with ID. One of these organizations was LiveWorkPlay, a charitable organization based in Ottawa (Ontario), which focuses on helping adults living with ID to integrate into the community (Live Work Play, 2013). The other organization, People First of Canada, has provincial and territorial chapters that strive for full inclusion of all people as equal members of the community (People First of Canada, 2006). During the recruitment phase, we attended a LiveWorkPlay Annual General Meeting in September 2012 to present Project Capabilities and to recruit participants. We also networked on social media and had Skype calls with People First of Canada members with whom we were unable to meet face-to-face due to distance.

An important lesson learned during the recruitment phase was the importance of establishing relationships with potential participants through face-to-face meetings and social media interactions before conducting the interviews. While the building of friendships with participants before interviewing runs counter to the advice of most research methodology textbooks, we found this was vital when working with a fragile population, such as with people with ID. Building upon these established relationships generated interest in what we do and created a feeling of trust with potential participants as the project got under way. We became part of the larger community that serves people with ID.

\section{First Interview}

The first interview allowed us to identify together the personal goals and ambitions of our participants. In contrast to traditional interviewing techniques, which suggest coming to the interview with a structured interview protocol in hand, we conducted our first interviews using a very unstructured format. We asked the participants broad and open-ended questions about their lives, hopes, and dreams, and achievements they were proud of. We allowed the participants to shape the course of the conversation, 
which allowed them to determine the topics and areas of interest that they felt were important.

During the interviews, we sought to build rapport with the participants by reciprocal sharing of information about our lives, rather than relying on a traditional one-way question-and-answer approach. We further sought to build reciprocity outside of the interviews through ongoing interactions with the participants by using online social networking through Facebook. We used Facebook to interact with participants in their day-to-day lives, learning about their hobbies, accomplishments, and other personal information, while simultaneously sharing information about our own lives. For example, upon meeting one participant for the first time, she said to Christina, "How is your dog doing?", having seen pictures posted on Facebook. The interviews therefore took on the feel of a discussion between friends, rather than a formal interview, which might have proven intimidating for the participants.

As Rubin and Rubin (2012) suggest, during the interviews, we used follow-up questions and probes to get additional details or depth and to encourage participants to share their thoughts. Many participants were surprised that we were interested in hearing about their lives. The participants were therefore initially shy and required prompting and encouragement to begin speaking. We also found that repeating phrases used by the interviewees was a helpful way to clarify their thoughts. For example: "You said that you got a career award at your job. Tell us more about that."

Another helpful approach in interviewing our participants was a technique from the collaborative inquiry and social engagement collection of tools developed by Chevalier and Buckles (2008). Participants were given three index cards and asked to write down three aspects of their lives that they were proud of. They were then asked to place each card on one point of a triangle of tape on the floor. Participants stood on the card that they were most proud of and explained why this made them proud. The use of physical space to represent aspects of their lives that participants were proud of helped them concentrate on the reasons why they were proud of these events or themes. This contributed to the selection of the topic of the self-advocacy video.

\section{Second Interview and Filming}

The specific topics identified during the first interview and subsequent email, and Facebook exchanges with the participants, allowed us to be more focused on a particular self-advocacy topic during the second interviews. The second interviews were filmed at a location chosen by the participant-usually their home or workplace. 
Below is an overview of the interview and filming process:

1) We used iPhones and iPads to film the participants as we interviewed them in more depth about their area of interest. We showed participants how to self-film on iPads, and they were able to film themselves saying whatever they wanted about their chosen topic without prompting from us. Some researchers have noted that video recording of interviewees often leads participants to become hesitant to speak (Rubin \& Rubin, 2012). In contrast, we were able to use video recording to our advantage by training the participants on how to use the technology themselves, and empowering them through self-recording. We told them if they made a mistake and wanted to start over, we could delete the clip and they could re-record. Because they were in control of the process, we found they opened up more, and were less shy in front of the camera.

2) We recorded the participants using our own iPhones. The unobtrusive nature of the iPhones made it easier for the participants to forget that we were filming, and allowed for the interview to unfold as a more natural conversation between friends.

\section{Creating the Self-Advocacy Videos}

Once all of the footage had been collected, we used Camtasia to create a video for each participant, which we uploaded on YouTube as private videos. Our goal was to create a video that truly represented the efforts of the participants as self-advocates. We operated under the motto "good enough is the new great" as coined by New York Times reporter Robert Mackey in 2009. Our intent was never to create professional videos. Rather, we wanted to create videos that represented the true nature of the participants' discourse, videos that they could share within the community and feel proud of.

When creating the videos, we felt it was important to use "I" language whenever text came across the screen. For example, saying "I invited Project Capabilities to my house" rather than "Cooper invited us to his house" completely changed the overall tone of the video. As researchers, we have a natural tendency to tell the "story" for the participant, rather than allowing the participant to tell his or her own story, from his or her perspective. When putting text on the screen, therefore, we made sure to use the participants' own words and tell it from their perspective. Once the videos were completed, they were uploaded to the Project Capabilities YouTube channel as private videos and shared with the participants for their approval and for the preparation of the next step. 


\section{Member Checking and Validation}

To proceed to member checking and validating the videos, the research team held a focus group that it called a "viewing party." Participants shared their initial thoughts about the videos and made suggestions for modifications. Reactions from the participants were overwhelmingly positive. For example, the research team showed one of the self-advocacy videos, and a conversation about independent living ensued. An excerpt from the focus group follows:

$\begin{array}{ll}\text { Participant: } & \text { He did a great job. Powerful. } \\ \text { Researcher: } & \text { Powerful message, to whom? } \\ \text { Participant: } & \text { To the community. To us. To LiveWorkPlay. I was thinking } \\ & \text { more to people with disabilities. Or people that have been } \\ & \text { told they may never live on their own. This gives hope that } \\ & \text { they may be able to live on their own. It also gives you a } \\ & \text { powerful message like saying you can be on your own } \\ & \text { and not move in a residence or not to give up. Because } \\ & \text { sometimes I feel like giving up and going into a [...] not a } \\ & \text { nursing home, but a group home like where I have my own } \\ & \text { apartment, but I go for meals downstairs and stuff like that. } \\ & \text { But that gives a message that I can cook on my own. }\end{array}$

\section{Community Reactions}

Following the focus group, the research team made the series of self-advocacy videos on the Project Capabilities YouTube channel public and shared the link with the LiveWorkPlay and People First of Canada communities on the Project Capabilities Facebook page. The self-advocacy videos can be viewed here:

- Cooper Gage (2 videos): http://youtu.be/bDqnyUcQZDU \& http://youtu.be/Vj38MK2DIcY

- Valerie Wolbert: http://youtu.be/-eWBhHiK2q4

- Paul Knoll: http://youtu.be/i50_C9ZTvcU

- Carl Sanderson: http://youtu.be/suj6LDzjrrY

- Ryan Nevitt: http://youtu.be/LevahXnP_4s

- Caroline Matte: http://youtu.be/t5IluY55VU0

- Daniel Pinsonneault: http://youtu.be/Ur4toFJ8mXw

- Gage Emond: http://youtu.be/VvPCfnY92h0 
We moderated comments on Facebook and YouTube that came both from members of the intellectual disabilities community, and from others outside the community. People congratulated participants for their courage, said that the self-advocacy videos were inspiring, and asked for more tips about independent living.

\section{Conclusion}

While conducting this study, we found that many of the traditional textbooks on interviewing for qualitative research did not meet the needs we faced when interviewing adults with ID. Instead, we drew on non-traditional techniques including motivational interviewing, collaborative inquiry, and social engagement tools as well as interactions outside the scheduled one-on-one interviews through social media to build rapport with participants. Rapport building was instrumental in allowing participants to feel comfortable with the researchers and take an active role in the development and creation of the self-advocacy videos. Using mobile technologies, such as iPads and iPhones, were also important factors in helping to build rapport, as they allowed participants to readily self-film, and permitted non-intrusive filming of interviews. Finally, social media platforms (Facebook and YouTube) allowed the participants to share their self-advocacy videos with the broader community, and to receive feedback from peers and other community members.

\section{Acknowledgment}

We would like to give a special thank you to the LiveWorkPlay community and People First of Canada. Without their collaboration, this study would not have been possible. 


\section{References}

Chevalier, J.M., \&Buckles, D.J. (2008). SAS2: A guide to collaborative inquiry and social engagement. Sage India and IDRC, Ottawa and New Delhi. Retrieved from: http://idl-bnc.idrc.ca/ dspace/bitstream/10625/35977/1/127554.pdf

Creswell, J. (2008). Educational research: Planning, conducting, and evaluating quantitative and qualitative research. Pearson Education: New Jersey.

Davidson, A.-L. (2012). Use of mobile technologies by young adults living with an intellectual disability: A collaborative action research study. Journal on Developmental Disability, 18(3), 21-32.

Davidson, A.-L. (2009a). Community and residential integration, and paid employment go hand-in-hand: A collaborative inquiry. Journal on Developmental Disabilities, 15(2), 27-37.

Davidson, A.-L. (2009b). Producing self-advocacy videos through a process of collaborative action research with adults living with an intellectual disability. International Journal of Learning, 16(9), 687-698.

Davidson, A.-L. (2009c). Why is it so hard to talk about our intellectual disability? A pilot study using action research. Journal on Developmental Disabilities, 15(1), 8-20.
Davidson, A.-L., Leblanc, R., Leno, S., Clément, N., Godbout, S., Moldoveannu, M., et al. (2004). Le projet "On Our Own Together II": à I'aube d'une ère nouvelle. Revue francophone de déficience intellectuelle, 15(2), 235-245.

Leblanc, R., Paruthi, R., Davidson, A.-L., Clément, N., Godbout, S., Leno, S., et al. (2008). The "On Our Own Together Housing Project" (Cooperative Housing for People with Intellectual Disabilities). Journal on Developmental Disabilities, 14(3).

Live Work Play. (2013). About LiveWorkPlay: An introduction. Retrieved from: http://livework play.ca/intro-about-us/

Mackey, R. (2009, December 13). Good enough is the new great. The New York Times.

Miller, W., \& Rollnick, S. (2013). Motivational interviewing: Helping people change (3rd ed.). The Guilford Press: New York.

Nussbaum, M. (2000). Women and human development: The capabilities approach. Cambridge, UK: Cambridge University Press.

People First of Canada. (2006). About us. Retrieved from: http://www.peoplefirstof canada.ca/visions_goals_en.php

Rubin, H., \& Rubin, I. (2012). Qualitative interviewing: The art of hearing data (3rd ed.). Los Angeles: Sage Publications.

Sen, A. (1992). Inequality reexamined. Boston: Harvard University Press.

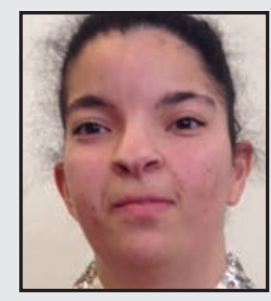

Stefanie Corona is an M.A. Educational Technology candidate in the Department of Education at Concordia University. She has a B.A. in Human Relations from Concordia University (2011). She is currently pursuing her thesis research on how instructor participation in a community of practice helps develop professional learning. Stefanie served as Chair of the 2013 Graduate Symposium in the Department of Education, which is an annual conference that provides students with the opportunity to showcase interdisciplinary research and foster collaboration. 


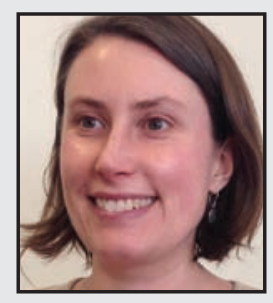

Christina Hannum is currently pursuing a Master's Degree in Educational Technology at Concordia University, where she is particularly interested in researching how mobile technologies can improve educational access for disadvantaged populations. Christina previously served for eight years as a Senior Manager with a non-profit microfinance organization, FINCA International, where she was responsible for managing global development projects to help people living in poverty develop employment skills and access financial services to start up small businesses. Christina has a Master's Degree in International Relations and Economics from Johns Hopkins University's School for Advanced International Studies (SAIS), and speaks Spanish and Portuguese.

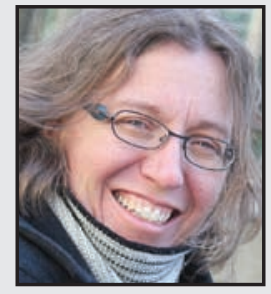

Ann-Louise Davidson, PhD, is an Associate Professor of Education at Concordia University where she teaches in the Educational Technology graduate program. Her research interests revolve around the changes brought by digital technologies in society and in the educational system, and their impact on how human beings learn individually and socially. She has published articles in the field of technology in education, including how teachers use technologies in pedagogical activities, how technologies can be used to learn, and how they can be used to design learning individually and in communities of practice.

LINK TO:

www.liveworkplay.ca

www.peoplefirstofcanada.ca 